\title{
AN ANALYSIS OF RECENT RESEARCH ON VENTURE CAPITAL NETWORKS
}

\author{
Salvatore POLIZZI (D) \\ Department of Economics, Business and Statistics, University of Palermo, \\ Viale delle Scienze - Building n. 13, 90044, Palermo, Italy \\ *E-mail: salvatore.polizzi@unipa.it
}

\begin{abstract}
Purpose - this paper examines recent trends in venture capital network research. Network analysis is a useful approach for analyzing inter-organizational networks, especially for venture capitalists, which are characterized by plenty of connections. Although important steps ahead have been made, several research questions are still unanswered.

Research methodology - this brief review analyses deeply three papers which are representative of the novel scientific literature in this field. Scrutinizing these works, I identify their points of strength and weaknesses, in order to understand how to pave the way for further research.
\end{abstract}

Findings - this paper shows that the study of network weak ties and the role of risk management strategies are promising areas for pushing the frontiers of research on venture capital networks.

Research limitations - although less recent papers are not considered in this analysis, the in-depth discussion of the latest research provides interesting insights and advice for scholars willing to do research on this field of studies.

Practical implications - extending our knowledge on this topic is crucial for understanding the best strategic decisions venture capitalists should take when operating within an inter-organizational network.

Originality/Value - this paper critically analyses steam of literature which is important from both scientific and managerial viewpoints. Furthermore, it poses questions to be addressed by future research.

Keywords: venture capital, private equity, network analysis, venture capital investments, risk management, interorganizational networks, venture capitalists' reputation, venture capital performance, network weak ties.

JEL Classification: G20, G24, G32, M10, M21, L14.

Conference topic: Contemporary Financial Management.

\section{Introduction}

Network analysis has assumed great importance over the last decades (Barabàsi, 2002; Newman, 2010). Early research shed lights on sociometry, psychology, and anthropology over the first half of the previous century (Borgatti, 2003). However, network analysis was not meant to be bound in such a small field of studies. Because of its characteristics, network analysis is extremely useful in management studies (Ahuja, Soda, \& Zaheer, 2012). Firms are characterized by several connections with other firms ${ }^{1}$ and their study is a crucial and challenging aim for business economists (Baker \& Faulkner, 2017). The first important seminal paper about inter-organizational networks has been the work of Powell, Koput and Smith-Doerr, 1996 "Interorganizational Collaboration and the Locus of Innovation: Networks of Learning in Biotechnology". After this milestone, several contributions have been written about this topic, but discussing them goes beyond the aim of this paper. As the title suggests, the focuses are on venture capitalists' networks. Venture capitalists are companies that are characterized by plenty of connections, with both other venture capitalists and their clients (i.e. the companies they invest in). Hence, applying network analysis on them is a straightforward and useful choice. Over the last few years, some authors have written interesting papers on venture capitalists' networks (one of the most recent paper is Gu \& Liu, 2019). They employed the methodological tools of the aforementioned network analysis to deal with some research issues about venture capitalists. In particular, their main objectives can be synthesized as follows:

\footnotetext{
${ }^{1}$ Typical connections are those with customer or supplier firms (vertical connections) or with companies that operate at the same level of the supply chain (horizontal connections).
} 
- Understanding whether or not the structure of the network influences somehow the performance of the venture capitalists and (if it is so) which kind of network structures is the best for different kind of venture capitalists;

- Assessing how the choices made by venture capitalists affects the structure of the network;

- Trying to analyze the relationships between the reputation of the venture capitalists and their role within the network;

- Analyzing the different risk management strategies to choose the companies to connect with.

The main aim of this brief review is to provide an overview of some of the most important of these research papers. However, in order to understand them properly, it is fundamental to know the basics of network analysis, at least the most important aspects related to inter-organizational networks (useful references are Amati, Lomi, \& Mascia, 2019; Djodat \& Zu Knyphausen-Aufseß, 2017; Provan, Fish, \& Sydow, 2007; Rosenkopf \& Padula, 2008; Wegner, de Mattos Zarpelon, Verschoore, \& Balestrin, 2017), and what a venture capitalist is, what it does and how it operates ${ }^{2}$.

It is important to notice that, these papers provide some very useful insights for further development of the research in this field, which still leaves some unanswered questions that could turn out to be crucial. However, even though this topic has been studied deeply in some aspects, there are several further investigations to carry out. Since venture capitalists' networks can be considered an open field of research, the analysis of the recent literature on this topic is useful to pave the way for further research on this topic.

The structure of the paper is organized as follows: section 1 provides some basics on (inter-organizational) network analysis; section 2 explains what venture capitalists are and how they operate; section 3 provides a brief review of the research on venture capital network; Section 4 concludes.

\section{Some basics on (inter-organizational) network analysis}

This section is meant to provide some useful introductory aspects. The main focus is on inter-organizational network analysis, which is characterized by some peculiarities that make it quite different from general network analysis. The definitions and methodologies explained in this section are fundamental to understand properly the third section of this paper.

Firstly, it is crucial to understand what is the network. A network can be defined as a set of nodes that are connected by different types of ties. In inter-organizational networks, nodes are companies and ties have to be interpreted as any type of (strong or weak) connection between them. Studying single firms is a fundamental step in business economics, but, in order to have a more general view of the industry, the study of the network is absolutely required ${ }^{3}$. However, studying a new phenomenon requires a new perspective and new methodological tools. Connections between companies can be classified as strong or weak ties (Levanti, 2010). Examples of strong ties are joint ventures, alliances, joint investments in special purpose vehicle or other sturdy relationships which are usually formalized through a contractual agreement (for further explanations on strong ties see Tiwana, 2008; Wuebker, Hampl, \& Wuestenhagen, 2015). On the other hand, weak ties are connections which are less strong and usually not formalized through contracts, for instance, a weak tie could be a personal friendship between two employees of different companies. Notice that it is much more difficult to study weak ties because most of the times the lack of data is an insurmountable issue. This is the reason why, most researchers deal with strong ties only and they deliberately ignore weak ties, even if it would be extremely useful studying them (Bužavaitė \& Korsakienè, 2018).

A crucial concept to be introduced is that of component: it is the maximal sets of nodes where each node is able to reach every other node by some path. In this regard, bridges are a very important type of tie: it is a tie which increases the number of components if it is removed. Roughly speaking, if there is the chance of creating several bridges within a network, the latter is said to be characterized by a structural holes configuration, whereas, if there is no such possibility, the network is said to be cohesive. However, it is important to notice that the cohesiveness is not a binary condition (cohesive or not cohesive network) but there is an indefinite set of configurations between these two extremes structures.

It is now important to introduce the measures of the degree centrality of a node within a network. It is a measure useful to assess how a node is well connected to the others. The first measure is closeness, which explains how long the information takes to get a certain location and how far a node is from the other nodes. Another powerful and popular measure is an eigenvector, which can be interpreted as the extent to which a node is connected to the other well-connected nodes. The study of these measures led to the definition of the core-periphery models, which is characterized by a single cohesive subgroup with sets of other nodes, which are connected to the core in a loose way. Hence, core members interact a great deal with each other, whilst the members of the periphery interact with a few core members (through bridges).

This somehow confusing set of new definitions and concepts about network analysis is absolutely partial and incomplete. The aim of this section is just reporting some introductory aspects to understand the research studies on venture capitalists' networks. ${ }^{4}$

\footnotetext{
${ }^{2}$ This is what sections 1 and 2 try to do.

${ }^{3}$ Network analysis can be extremely useful also for competition studies. In this perspective, a trustworthy reference is Porter (2008).

${ }^{4}$ For further information on interorganizational networks, see also Dagnino et al. (2015), Mariotti \& Delbridge (2012).
} 


\section{Understanding venture capitalists}

The aim of this section is to enable the reader to have a general idea of what a venture capitalist is, what it does and how it operates. The topics reported here are far from being complete and exhaustive. The reader must content him/herself with some introductory aspects useful to fully understand the remainder of the paper.

Venture capitalists are institutional investors whose business objective is investing in the equity capital of unlisted companies, with the final aim of making the investee grow and, in the medium-long term, sell the shares either in a regulated market through an Initial Public Offering (IPO) or to other investors, without any stock exchange listing. Especially in Europe, scholars use to distinguish between venture capital and private equity (Gervasoni \& Sattin, 2008); the latter is a more general term which is utilized to identify investments in any period of the life of the company, whereas venture capital refers to investments during the start-up phase only. However, this slight distinction will not be considered here. Going back to the description of the activity of the venture capitalists, it is important to focus on the advisory services they supply to the companies they invest in. Exactly because they want the company to grow, they work in strict collaboration with the board of directors $^{6}$ of the investee in order to be sure that they will make optimal (or, at least, rational) economic decisions. Thus, it seems reasonable that because of their role and activity, venture capitalists operate in a large network made up by other venture capitalists and by the investee companies. Venture capital does not provide only funding, it is a valuable source of strategic organizational and financial skills, managerial know-how and, most important, a network of contacts.

Trying to give a general overview of the phases of the venture capital process, six steps can be identified:

- Deal flow, it "describes the rate at which business proposals and investment pitches are being received by financiers"

- Selection of the companies that deserve further evaluation before choosing whether or not to invest in them;

- Due diligence, it is the process which consists in evaluating the company looking at its financial and economic conditions and in estimating the risks the eventual acquisition would generate;

- Investment decision, it is the final decision to invest or not to invest in the company;

- Monitoring, this fundamental phase is not only about observing the behavior of the investee, because venture capitalists do have an active role in providing advises within the board of directors itself;

- Divestment, after the investee has grown enough, the venture capital decides to exit the investment, selling the stocks/shares of the company to other investors.

After this brief description, it is straightforward to identify some of the most valuable resources and skills for venture capitalists' success. It is trivial to understand that the right choice of risk (or uncertainty) management strategies is crucial for venture capitalists. They are fundamental to identify the best companies to invest in and to compute the costs-benefits analysis. As for risk management ${ }^{9}$, it is crucial to notice that, even if an investment is considered convenient, it may happen that one single venture capitalist is not willing to invest in a company all by itself. In certain circumstances, it is likely that two or more venture capitalists share costs and benefits (and risks) of investment and decide to invest together in one company, reducing their level of commitment. Another valuable intangible resource for venture capitalists is its maturity (and its status). The more mature the investor is, the more likely it is that its investment will be remunerative. Good investments require a high level of managerial skills and acquiring these skills usually takes time. Hence, venture capitalists tend to collaborate with venture capitalists with a similar degree of maturity and status, because they do not want to invest with lower status investors and higher status investors do not want to invest with them ${ }^{10}$.

The aspects outlined above are some of the forces that are able to shape the network structures of venture capitalists $^{11}$.

\section{A review of the research on venture capital network}

This section explains how scholars study and do research on venture capitalists' network. In particular, three recent papers are deeply analyzed. For each of them, a discussion is provided, trying to figure out which are the advantages and the drawbacks of their approaches and assessing how and to what extent they provided contributions to the extant

\footnotetext{
${ }^{5}$ For deeper explanations on this topic see Ozmel, Reuer, \& Gulati (2013).

${ }^{6}$ Actually, venture capitalists often have the responsibility to propose some appointments to the management boards. For a wider description of the relationships between firms and financial intermediaries see Scannella (2016).

${ }^{7}$ See the enacademic website for further information: http://enacademic.com/dic.nsf/enwiki/1037218/Deal_flow

${ }^{8}$ About this aspect, notice that, in situations like these, investors have to choose under uncertainty conditions or even under ambiguity conditions, defined as the "lack of clarity about the meaning and implications of particular events or situations" by Santos \& Eisenhardt (2009).

${ }^{9}$ Another suggestion for further research on this topic is to focus on the risk management strategies and processes companies need to apply when they operate within a network. It seems that this field of research is not considered properly by scholars.

${ }^{10}$ Even though maturity and status are two different concepts, some authors argue that for venture capitalists these two variables are highly correlated. For further information see Petkova et al. (2014).

${ }^{11}$ For further information on the importance of the structure of the network, a trustworthy reference is Capaldo (2007).
} 
literature. Moreover, an effort in identifying open problems for further research is made. The choice of analyzing only three papers rely on the fact that they are representative of the recent trends of the scientific literature on this topic. Thus, analyzing other papers would not add anything interesting for the conclusions of this work ${ }^{12}$.

The title of the first paper analyzed is "Whom You Know Matters: Venture Capital Networks and Investment Performance" written by Hochberg, Ljungqvist, and Lu in 2007. This research is conducted on a sample consisting of 3.469 venture capital funds, whose headquarters are located in the United States, that were started between 1980 and 1999 . The authors found that better-networked venture capitalists ${ }^{13}$ experience significantly better performances, as measured by the proportion of investments that are profitably exited through an IPO or a sale to other investors. In a similar way, the portfolio companies of better-networked venture capitalists are more likely to survive to subsequent financing and eventual exit. As a risk management strategy, venture capitalists tend to syndicate their investments with other venture capitalists, rather than investing alone. There are three reasons why syndication networks are useful. First of all, venture capitalists co-invest in their deals in the expectation of future reciprocity (Lerner, 1994). Secondly, in order to check each other's willingness to invest in potentially promising companies, venture capitalists can pool correlated signals and select only the best investments in contexts of extreme uncertainty. Thirdly, individual venture capitalists use to have investment knowledge that is sector-specific and location-specific. Syndication spreads information across industries boundaries and enables venture capitalists to diversify their portfolio of investments. In order to measure centrality, the authors utilize the aforementioned eigenvector centrality, whilst exit rates are their measure of performance ${ }^{14}$. One of the main findings of the paper is that a one standard deviation increase in network centrality leads to an increase in exit rates of about 2.5 percentage. Hence, the centrality of the venture capitalist within the network plays an important role in influencing its performances. This is probably due to the fact that well-networked venture capitalists are able to provide better advisory services to their portfolio companies. Another explanation for the better performance of well-connected venture capitalists may be related to their maturity. It seems reasonable that the centrality of a venture capitalist in the network is highly correlated with its experience. In order to exclude the possibility that the measures of network centrality are a proxy for experience, the models utilized by the author's control for a variety of dimensions of venture capitalists' experience. The findings of the authors suggest that improving the network position (i.e. being closer to the core of the network) must be a fundamental strategic consideration for any venture capitalist and it is a quite strong barrier to entry for new venture capitalists. This research is absolutely brilliant and it is one of the most important in this field of research. They adopted a traditional network analysis approach and their findings are important, without any doubt. This paper has provided a crucial contribution to the extant literature because in 2007 the authors who were writing about this topic were just a few. In particular, the study of the correlation between venture capitalists' network centrality and performances is supported by a theoretical point of view, but it is quite difficult to verify empirically. Moreover, this paper has paved the way for other research on this topic. However, this work is characterized by some drawbacks. From a methodological point of view, even though the authors tried to exclude the possibility that the measure of network centrality is a proxy for experience, it is difficult to be sure about this aspect. Furthermore, it seems reasonable that network centrality is also a proxy for reputation and the author did not compute any robustness check on this aspect ${ }^{15}$. Another critical issue is the sample. Even though the period analyzed is long, the cross-sectional dimensions of the sample are characterized by the problem that they care about U.S. venture capitalists only. There is no guarantee that the same results hold in different countries. Lastly, there are many unanswered questions (as the authors themselves admit):

- There is not any reference to informal or weak ties (such as interpersonal networks);

- There is no analysis on the cost venture capitalists have to afford in order to become well-connected to the core of the network;

- An explanation on how to connect with influential (and central) venture capitalists is missing as well.

The next paper to be analyzed is Petkova, Wadhwa, Yao, and Jain (2014) "Reputation and decision making under ambiguity: a study of U.S. venture capital firms' investments in the emerging clean energy sector". In this paper, the authors argue that a firm's reputation exerts dual pressure on its decision making under ambiguity conditions. In particular, on the one hand, reputation increases the firm's aspirations for future performance and its engagement in riskier strategies to achieve them. On the other hand, preserving the established reputation requires companies to deliver consistent performances over time, which, in turn, promotes greater use of risk reduction and mitigation strategies. The analysis is conducted on a sample of U.S. venture capitalists' investments in the clean energy industry for a time period running from 1990 to 2008 . Their main finding is that while high reputation venture capitalists are more likely to invest in the aforementioned emerging industry, they also employ risk reduction strategies more extensively. The authors measure the reputation of the venture capitalist within the network utilizing the measure proposed by Lee, Pollock, and Jin (2011), which is a composite index that takes into account the centrality of the venture capitalist in the network and its maturity. Ambiguity is typically experienced in situations characterized by novelty, complexity, or insolubility, and, of course, the clean energy industry in that period was characterized by these conditions. Unlike situations of uncertainty, where decision-makers can recognize and guess somehow the desired outcomes and the means to achieve them,

\footnotetext{
${ }^{12}$ For other recent papers on this topic see also Bottazzi, Da Rin, \& Hellmann (2016), Cox Pahnke et al. (2015), Zhelyazkov \& Gulati (2016).

${ }^{13}$ Notice that the authors take into account only strong and formal ties (such as alliances and joint ventures).

${ }^{14}$ Exit rate is generally accepted as the best measure for venture capitalists' performances.

15 They probably did not care about reputation because it is extremely difficult to quantify it in a reliable way. However, in the next paragraph, another research paper which deals with this problems is analysed.
} 
but cannot predict the probability of a specific outcome, in ambiguity situations companies lack even the understanding of which outcomes are worth or better pursuing (Weich, 1995). This situation is quite complicated because the ambiguity in an emerging industry leaves significant room for interpretation, and venture capitalists can vary in their assessment of the attractiveness of the emerging sector and in the selection criteria that they consider to be relevant and useful. The wish to discover the "next big thing" is a strong incentive for high reputation venture capitalists to channel their investments towards emerging industries. Another crucial aspect to consider is related to the need to meet high shareholders' expectations. Furthermore, high reputation improves venture capitalists' abilities to raise funds and increases the availability of resources to explore new opportunities. Hence, a virtuous cycle comes up. For these reasons, the first hypothesis of the authors is the following "Hypothesis 1: the higher the reputation of a venture capital firm, the higher the likelihood that it will invest in an emerging sector". If this hypothesis turns out to be verified, another problem may arise: if decision making under ambiguity is challenging for any venture capitalist, the more reputable ones are likely to perceive such decisions as riskier because of the potential reputation damage they may incur. Business economists suggest that there are essentially three risk reduction strategies venture capitalists can adopt: syndication, later stage investment, and low levels of commitment (Wadhwa \& Basu, 2013, Sorenson, 2001). Even if a venture capitalist with a high reputation might be more likely to invest in an emerging industry, because of its high aspiration, it is also likely to make greater efforts in order to manage the risks of these investments to balance the exploration of new opportunities with the pressures towards good performances. The second hypothesis of the authors follows: "Hypothesis 2. The higher the reputation of a venture capital firm, the greater its use of (a) syndication and (b) later stage investment, and (c) the lower its levels of commitment when investing in an emerging sector". Another important aspect to be considered is the sector legitimation, which, according to the authors can be synthesized through three variables: media attention, regulatory approval, and actions of peers. Because of the importance of sector legitimation, the third hypothesis of the authors is: "Hypothesis 3. Sector legitimation will increase the likelihood of a venture capital firm investing in an emerging sector" ${ }^{\prime 6}$. In order to test the aforementioned hypotheses, they carried out a random effects panel linear regression, a simple logistic regression and they calculated the correlation matrix. Hypothesis 1 is verified because the authors found that a venture capitalists' reputation has a positive and significant effect on its likelihood to invest in an emerging industry. In support of hypotheses $2 \mathrm{a}$ and $2 \mathrm{~b}$, venture capitalist's reputation has positive and significant effects on the use of syndication, and about hypothesis $2 \mathrm{c}$, it is supported as well because reputation turns out to have a negative and significant effect on the level of commitment. The authors also find support for hypothesis 3, which predicts a positive effect of sector legitimation on a venture capitalists' likelihood to invest in companies belonging to an emerging industry. Hence, the results show that high reputation venture capitalists are more likely to invest in an emerging sector, and they tend to use risk reduction strategies in a more extensive way. The research conducted by the authors provides some useful insights for venture capitalists' network analysis. It is important to recognize that also this research has provided an important contribution to the extant literature. It analyses deeply the role of reputation to explain venture capitalists' performances. Reputation is a very important aspect in venture capitalists' networks and it is strictly related to the network centrality analyzed in the paper of Hochberg et al. 2007. Overall, this paper provides a complementary analysis to the research proposed by Hochberg et al., and it overcomes one of its main limitations: it was fundamental to quantify the role of reputation to explain more deeply venture capitalists' superior performances. This work is well done, but it is characterized by some drawbacks. Firstly, from a methodological point of view, all the results hold only if the measure of the venture capitalists' reputation proposed by Lee at al. is truly reliable. It is important to realize that reputation is very difficult to quantify. This is a crucial point in the analysis. It would be interesting to compute some robustness test utilizing other measures of reputation and to check whether or not the results still hold. Another drawback is related to the choice of restricting the analysis to three risk reduction strategies only. There are many other risk reduction strategies to be considered and excluding them is a strong limitation for this research. Another limitation is related to the sample: an intercountry sample would provide more robust results. The authors themselves recognize the last limitation. They just care about the reputation of the venture capitalists as a whole, but they do not analyze the reputation of individuals that work inside the company. Actually, it may happen that this kind of reputation is somehow significant within the network. Hopefully, future research could overcome these drawbacks.

The last research paper analyzed is Bellavitis, Filatotchev, and Souitaris, 2017, "The impact of investment networks on venture capital firm performance: a contingency framework." This work aims at investigating the role of both venture capitalists' maturity and status to explain venture capitalists' superior performances. In particular, the authors study the effects of these two proxies for firm-level resources on the relationship between network cohesion and venture capitalists' performances. They show that status and maturity simultaneously determine the performance effects on network cohesion. The most popular way to create connections between venture capitalists is utilizing syndicates (Hochberg et al. 2017). When choosing the partner to invest with, a venture capitalist has to decide whether it wants to invest with partners that are already in its network (making the network more cohesive) or to establish a new connection with a firm which is outside the network (creating a network richer in structural holes). Both these choices have their points of strength and drawbacks. A cohesive network is useful to its members because it creates an environment of trust and facilitates the flow of resources and competencies within the network. Unfortunately, a network

\footnotetext{
${ }^{16}$ There are other hypothesis tested by the authors, but analysing them would not add anything interesting for the analysis of this paper.
} 
too cohesive puts a constraint on the flexibility of the actors and on the scope of exchange in non-redundant resources. On the other hand, a network which is rich in structural holes supplies non-redundant resources and permits brokerage opportunities that may be beneficial for network members. This paper shed the lights on the effect of the structural characteristics of venture capitalists' syndication networks on the performance of individual venture capitalists and on the trade-offs associated with different network structures. More specifically, the authors focus on maturity and status as important firm-level factors that can help to determine the balance between the benefits and the costs associated with network structure characteristics. Their research question is the following "What are the effects of the local venture capital firm's maturity and status on the relationship between network cohesion (versus structural holes) and venture capitalists' performance?". The authors test their hypotheses on a sample of venture capital investments in the United Kingdom. For each venture capitalist, they construct its time-varying syndication network and computer network cohesion and status. The performance measure adopted is the exit rate also in this case. The main finding of the research is that lower status and younger venture capitalists experience better performances when they operate in a cohesive network with other venture capitalists, whereas a network rich in structural holes is more beneficial for higher status and more mature venture capital investors. Moreover, utilizing a three-way interaction model, the authors show that maturity and status have joint effects in terms of shaping the cost-benefit trade-offs associated with cohesion or structural holes within venture capitalists' networks. Typically, young venture capitalists have less financial resources than mature ones. Furthermore, mature investors, because of their experience, are in a much better position to evaluate deals and, as a consequence, to add value to their portfolio companies, guiding them to a successful and remunerative exit. On the other hand, young venture capitalists can mitigate the drawbacks related to their lack of internal resources, if they operate in a cohesive network. However, although the socially embedded mechanism of reciprocal support of cohesive networks is fundamental over the early phases of the venture capitalist' development, it could limit its flexibility and opportunities during the maturity phases. In particular, it is likely that a mature venture capitalist requires less support from the network. Rather, it does need opportunities to grow and sustain its performances, and a network rich in structural holes should provide better access to these opportunities. This reasoning leads the authors to test the following hypothesis: "H1: The relationship between venture capital network cohesion and individual venture capital firm performance is contingent on the firm's maturity. Specifically, for younger (more mature) venture capital firms, membership in a cohesive (structural holes) network improves performances". The authors define status as a "socially constructed, intersubjectively agreed upon and accepted ordering or ranking in a social system". Within the venture capital industry, centrally positioned firms enjoy high status because they have a prominent position in the network. On the other hand, lower status venture capitalists are less attractive partners, and they are in a disadvantageous position in terms of both quality and number of potential deals. However, network cohesion provides a mechanism which creates resource spill-overs, legitimacy and visibility to low-status venture capitalists. Hence, the authors argue that low-status venture capitalists are in the position to overcome the drawbacks of their status if they operate in a cohesive network, whilst, high-status venture capitalists do have the power to receive a large number of qualitatively good coinvestment deals, also in a network reach in structural holes. For such investors, a cohesive network is a sort of constraint, because it leads them to co-invest with their closer alliances because of the existing relationships. In contrast, a structural hole network offers the resources they need the most. Furthermore, connecting with firms that are distant in the network, they can exploit new non-redundant resources and information. This reasoning leads the authors to hypothesize that " $\mathrm{H} 2$ : the relationship between venture capital network cohesion and individual venture capital firm performance is contingent on the firm's status. Specifically, for lower (higher) status venture capital firms, membership in a cohesive (structural holes) network improves performance." The most interesting part of this paper is probably the discussion of the third hypothesis. The authors extend the claims of the other two hypotheses, suggesting that the effects of a venture capitalist's status and maturity are reciprocally reinforcing. In order to fully exploit the opportunities of a network rich in structural holes, a venture capitalist needs to have both a high maturity and a high status. Hence, there may be a three-way interaction between status, maturity and network structure. In ideal situations, high status combined with maturity and structural holes network will boost the venture capitalist's performances. On the other hand, investors operating in intermediate situations ${ }^{17}$ might be in trouble outside a network which is not cohesive. Hence, the third hypothesis of the authors is the following: "H3: The relationship between venture capital network cohesion and individual venture capital firm performance is contingent on the interaction of the firm's maturity and status." The sample includes all venture capitalists investing in United Kingdom start-ups from 1998 to 2008 . The performance measure chosen is the number of exits, also in this case. In order to measure network cohesion, they utilized the index suggested by Burt 1992. This index measures how redundant is the relationship between venture capitalists. To determine the venture capitalist's maturity, the authors use the number of funds under management at a given time ${ }^{18}$. The measure adopted for status is Bonacich's centrality (Bonacich \& Power, 1987), which is very similar to the measure adopted by Petkova et al. 2014. Because of the endogeneity of the variables, the authors decided to utilize a generalized two-stage least squares random effects instrumental variables regression. In particular, the instru-

\footnotetext{
${ }^{17}$ High status and low maturity or vice versa.

${ }^{18}$ The authors argue that it is a better proxy of maturity than age, because it represents the amount of internal resources available to the venture capitalists.
} 
ments utilized were average syndicate size, pension funds assets under management as a percentage of GDP and corporate venture capital type. Through this approach, the authors have been able to verify that hypothesis 1 is correct because the interaction coefficient was highly significant. Supporting hypothesis 2 , the two-way interaction between a cohesive network and status on performance was highly significant as well. Most important, the authors find support also for hypothesis 3 . The three-way interaction term was negative and significant. The negative sign indicates that status and maturity (if they are taken together) reinforce the advantages of a structural holes position. Hence, to fully exploit a network rich in structural holes, a venture capitalist needs both a high level of status and maturity. If the investor has low status and low maturity, or if it is in an intermediate position, it benefits more from a cohesive network. This paper represents an important step ahead for the literature on venture capitalists' network. It is the first research paper which focuses on the importance of the interactions between the variables analyzed. Previously, scholars considered status and maturity as two (almost) identical variables, even though they are completely different. It must be acknowledged that it is fundamental (and more correct) to study these variables as separated ones and to deal with their interactions. In particular, the finding that high status alone is not enough for a venture capitalist to benefit from a structural holes network is a very important result. It is a crucial point for venture capitalists, and also for an eventual orchestrator of the investors' network (Paquin \& Howard-Grenville, 2013). This result provides valuable information also for policymakers, helping them in their decision-making process. However, also this paper is characterized by some drawbacks. Firstly, as the authors themselves recognized, it is extremely difficult to find reliable instrumental variables in such a complex setting. For this reason, it is almost impossible to be sure that the instruments proposed are the optimal ones. The same reasoning applies to the measures of performance, network cohesion and, most important, status. Another critique is related to the sample, which is single-country also in this case. It would have been useful to analyze a cross-country sample. Another limitation is related to the fact that, also, in this case, the focus is on formal and strong ties. The authors deliberately exclude any type of informal or weak tie. It would be extremely interesting to investigate this aspect, which is neglected by most of the scholars for lack of data only, not for theoretical reasons. Thus, it is absolutely necessary to find a way to gather data on weak and informal ties and to assess whether or not they can add something interesting to network analysis ${ }^{19}$.

\section{Conclusions}

This paper has provided an overview of some of the most recent and important works on venture capitalist network. The first two sections have been two preparatory sections whose main aim was to explain some introductory concepts useful to understand the remaining part of the paper. This paper has analyzed deeply three of the most recent and important contributions to venture capitalist network analysis.

Analyzing the recent tendencies and the unanswered questions are crucial aspects to understand the methodologies applied to extend our knowledge in this interesting field is a necessary and useful step to pave the way for further developments.

To my best knowledge, Hochberg et al. 2007 is the first paper which shed the lights on the role of network centrality in explaining venture capitalists' performances. The idea behind this research is brilliant even if it has been misleading to focus only on internal resources to explain venture capitalists' performances. Dealing with the position of the venture capitalist within the network is a fundamental aspect to be taken into account. It was a seminal paper which required several improvements in the methodological aspects. Petkova et al. 2014 have provided development to this field of research, studying the role of reputation inside the network under conditions of ambiguity. According to them, network centrality is not enough. Even if it is strictly related and highly correlated with network centrality, it is something different which deserves attention by scholars. Reputation is a valuable intangible asset which can partially explain the superior performances of a venture capitalist. However, analyzing single aspects separately is not the best way to study inter-organizational networks. There are several variables to take into account, and dealing with their interactions is as much important as studying them separately. This is the reason why Bellavitis et al. 2017 analyses the interaction between venture capitalists' status and maturity. Their important finding is related to the fact that venture capitalists that are both high status and mature will benefit from a network rich in structural holes, whereas low status and less mature firms (and also those in intermediate positions) will benefit from a cohesive network. Taking into account the structure of the network is crucial, and it deserves further efforts by scholars.

In order to pave the way for further research in this field, it is possible now to outline some important aspects and unanswered questions. Firstly, it is fundamental to analyze in a more detailed way the role of risk reduction strategies in venture capitalists' network. Petkova et al. deal with just a small subset of them. It would be extremely interesting to study the effects of risk management strategies in venture capitalists' performances because investors adopt different risk management strategies in different network structure and in different network positions. Furthermore, also, in this case, it would be useful to check whether or not there is any kind of interaction with other variables, such as firm's dimension, status, and maturity. Another crucial aspect is related to the study of weak or informal ties, which is usually neglected by most of the researchers because of the lack of available data. Without any doubt, they are a fundamental

\footnotetext{
${ }^{19}$ This is a general statement for any interorganizational network, it is not related to venture capitalists' network only.
} 
aspect of network analysis. It may happen that an informal tie (for instance a personal friendship) has a stronger impact than a tie which is supposed to be strong. For this reason, it is fundamental to study weak ties ${ }^{20}$. Even though the methodologies adopted to analyze them will always be subject to critiques, it is necessary to make an effort and try to study their effects and the structure of the network they create. Notice that weak ties are characterized by advantages and disadvantages. In particular, since they usually require a small amount of effort (both in terms of money and time), they are, in some sense, less risky. On the other hand, because of the lack of a written contract ${ }^{21}$, the outcomes of the relationships cannot be defined clearly, therefore they could be considered riskier than strong ties. Hence, the two aforementioned proposals of dealing with risk management strategies in investors' networks, and of studying weak ties, might be combined in order to analyze how investors utilize weak ties for risk management purposes. These are just a few of many proposals that could be made for enhancing further developments in this interesting field of research, which is still full of 'structural holes'.

\section{Disclosure statement}

No competing financial, professional, or personal interests from other parties to disclose.

\section{References}

Ahuja, G., Soda, G., \& Zaheer, A. (2012). The genesis and dynamics of organizational networks. Organization Science, 23(2), 434448. https://doi.org/10.1287/orsc.1110.0695

Amati, V., Lomi, A., \& Mascia, D. (2019). Some days are better than others: Examining time-specific variation in the structuring of interorganizational relations. Social Networks, 57, 18-33. https://doi.org/10.1016/j.socnet.2018.10.001

Baker, W. E., \& Faulkner, R. R. (2017). Interorganizational networks. The Blackwell companion to organizations, 520-540.

Barabàsi, A. L. (2002). Linked: The new science of networks. Cambridge, MA: Perseus.

Bellavitis, C., Filatotchev, I., \& Souitaris, V. (2017). The impact of investment networks on venture capital firm performance: A contingency framework. British Journal of Management, 28(1), 102-119. https://doi.org/10.1111/1467-8551.12162

Bonacich, P. (1987). Power and centrality: A family of measures. American Journal of Sociology, 92, 1170-1182, Chicago. https://doi.org/10.1086/228631

Borgatti, S. (2004). Social network analysis. Boston: Carroll School of Management.

Borgatti, S. (2003). The state of organizational social network research today. Boston: Organizational Studies.

Bottazzi, L., Da Rin, M., \& Hellmann, T. (2016). The importance of trust for investment: Evidence from venture capital. The Review of Financial Studies, 29(9), 2283-2318. https://doi.org/10.1093/rfs/hhw023

Burt, R. S. (1992). Structural holes. Cambridge: Harvard University Press.

Bužavaite, M., \& Korsakienè, R. (2018). Inter-personal and inter-organizational networks in internationalization of SMEs: A bibliometric analysis and review. Open Economics, 1(1), 94-104. https://doi.org/10.1515/openec-2018-0003

Capaldo, A. (2007). Network structure and innovation: The leveraging of a dual network as a distinctive relational capabilities. Strategic Management Journal, 28, 585-608. https://doi.org/10.1002/smj.621

Cox Pahnke, E., McDonald, R., Wang, D., \& Hallen, B. (2015). Exposed: Venture capital, competitor ties, and entrepreneurial innovation. Academy of Management Journal, 58(5), 1334-1360. https://doi.org/10.5465/amj.2012.0777

Dagnino, G. B., Levanti, G., Minà, A., \& Picone, P. M. (2015). Interorganizational network and innovation: A bibliometric study and proposed research agenda. Journal of Business \& Industrial Marketing, 30(3/4), 354-377. https://doi.org/10.1108/JBIM02-2013-0032

Djodat, N., \& Zu Knyphausen-Aufseß, D. (2017). Revisiting Ghoshal and Bartlett's theory of the multinational corporation as an interorganizational network. Management International Review, 57(3), 349-378. https://doi.org/10.1007/s11575-016-0298-3

Gervasoni, A., \& Sattin F. L. (2008). Private equity e venture capital. Milan: Guerini e Associati.

Granovetter, M. S. (1977). The strength of weak ties. Social Networks, 347-367. https://doi.org/10.1016/B978-0-12-442450$0.50025-0$

Gu, W., \& Liu, J. (2019). Exploring small-world network with an elite-clique: Bringing embeddedness theory into the dynamic evolution of a venture capital network. Social Networks, 57, 70-81. https://doi.org/10.1016/j.socnet.2018.11.002

Gulati, R., Sytch, M., \& Tatarynowicz, A. (2012). The rise and fall of small worlds: Exploring the dynamics of social structure. Organization Science, 23(2), 449-471. https://doi.org/10.1287/orsc.1100.0592

Hochberg, Y. V., Ljungqvist, A., \& Lu, Y. (2007). Whom you know matters: Venture capital networks and investment performance. The Journal of Finance, 62(1), 251-301. https://doi.org/10.1111/j.1540-6261.2007.01207.x

Lee, P. M., Pollock, T. G., \& Jin, K. (2011). The contingent value of venture capitalist reputation. Strategic Organization, 9, 33-69. https://doi.org/10.1177/1476127011400505

Lerner, J. (1994). The syndication of venture capital investments. Financial Management, 23, 16-27. https://doi.org/10.2307/3665618

\footnotetext{
${ }^{20}$ Scholars have been shown the importance of weak ties in other fields of research. An interesting sociological example is Granovetter (1977).

${ }^{21}$ Which would make the tie formal/strong.
} 
Levanti, G. (2010). Il governo dei sistemi reticolari di imprese. Milan: Franco Angeli.

Mariotti, F., \& Delbridge, R. (2012). Overcoming network overload and redundancy in interorganizational networks: The roles of potential and latent ties. Organization Science, 23(2), 511-528. https://doi.org/10.1287/orsc.1100.0634

Newman, M. (2010). Networks: An introduction. Oxford: OUP. https://doi.org/10.1093/acprof:oso/9780199206650.001.0001

Ozmel, U., Reuer, J. J., \& Gulati, R. (2013). Signals across multiple networks: How venture capital and alliance networks affect interorganizational collaboration. Academy of Management Journal, 56(3), 852-866. https://doi.org/10.5465/amj.2009.0549

Paquin, R. L., \& Howard-Grenville, J. (2013). Blind dates and arranged marriages: Longitudinal processes of network orchestration. Organization Studies, 34(11), 1623-1653. https://doi.org/10.1177/0170840612470230

Petkova A. P., Wadhwa, A., Yao X., \& Jain, S. (2014). Reputation and decision making under ambiguity: A study of US venture capital firms' investments in the emerging clean energy sector. Academy of Management Journal, 57(2), 422-448. https://doi.org/10.5465/amj.2011.0651

Porter, M. E. (2008). Competitive strategy: Techniques for analyzing industries and competitors. New York: Simon and Schuster.

Powell, W. W., Koput, K. W., \& Smith-Doerr, L. (1996). Interorganizational collaboration and the locus of innovation: Networks of learning in biotechnology. Administrative Science Quarterly, 41, 116-145. https://doi.org/10.2307/2393988

Powell, W. W., Koput, K. W., White, D. R., \& Owen-Smith, J. (2005). Network dynamics and field evolution: The growth of interorganizational collaboration in the life sciences. American Journal of Sociology, 110(4), 1132-1205. https://doi.org/10.1086/421508

Provan, K. G., Fish, A., \& Sydow, J. (2007). Interorganizational Networks at the network level: A review of the empirical literature on whole networks. Journal of Management, 33, 479-516. https://doi.org/10.1177/0149206307302554

Rosenkopf, L., \& Padula, G. (2008). Investigating the microstructure of network evolution: Alliance formation in the mobile communications industry. Organization Science, 19(5), 669-687. https://doi.org/10.1287/orsc.1070.0339

Santos, F., \& Eisenhardt, K. (2009). Constructing markets and shaping boundaries: Entrepreneurial power in nascent fields. Academy of Management Journal, 52, 643-671. https://doi.org/10.5465/amj.2009.43669892

Scannella, E. (2016). Il rapporto banca-impresa: Aspetti definitori e premesse teorico-metodologiche. Economia-Ricerche, 1, 1348.

Sorenson, O., \& Stuart, T. E. (2001). Syndication networks and the spatial distribution of venture capital investments. American Journal of Sociology, 106, 1546-1588. https://doi.org/10.1086/321301

Tiwana, A. (2008). Do bridging ties complement strong ties? An empirical examination of alliance ambidexterity. Strategic Management Journal, 29(3), 251-272. https://doi.org/10.1002/smj.666

Wadhwa, A., \& Basu, S. (2013). Exploration and resource commitment in unequal partnerships: An examination of corporate venture capital investments. Journal of Product Innovation Management, 30, 916-936. https://doi.org/10.1111/jpim.12037

Wegner, D., de Mattos Zarpelon, F., Verschoore, J. R., \& Balestrin, A. (2017). Management practices of small-firm networks and the performance of member firms. Business: Theory and Practice, 18, 197. https://doi.org/10.3846/btp.2017.021

Wuebker, R., Hampl, N., \& Wuestenhagen, R. (2015). The strength of strong ties in an emerging industry: Experimental evidence of the effects of status hierarchies and personal ties in venture capitalist decision making. Strategic Entrepreneurship Journal, 9(2), 167-187. https://doi.org/10.1002/sej.1188

Zhelyazkov, P. I., \& Gulati, R. (2016). After the break-up: The relational and reputational consequences of withdrawals from venture capital syndicates. Academy of Management Journal, 59(1), 277-301. https://doi.org/10.5465/amj.2013.0768 